\title{
Incidence of and defoliation by a newly introduced pest, Paropsisterna variicollis (Coleoptera: Chrysomelidae), on eleven durable Eucalyptus species in Hawke's Bay, New Zealand
}

\author{
H. Lin, T.J. Murray and E.G. Mason \\ New Zealand School of Forestry, University of Canterbury, Private Bag 4800, Christchurch \\ 8140, New Zealand \\ Corresponding author: tara.murray@canterbury.ac.nz
}

\begin{abstract}
In March 2016, an incursion of the paropsine beetle Paropsisterna variicollis (eucalyptus variegated beetle) was detected in the Hawke's Bay during routine Forest Biosecurity Surveillance. Paropsines cause significant damage to eucalypt plantations in several parts of the world. A survey of three Hawke's Bay sites containing 11 durable eucalypt species was conducted in January 2017. Defoliation by paropsines, and numbers of eggs, larvae and adults were recorded. Adult Pst. variicollis were observed on all eucalypt species, and were present in larger numbers than Paropsis charybdis in two sites. Eucalyptus bosistoana sustained the greatest defoliation and incidence of eggs and larvae, and E. macrorhyncha the least. Parasitism of Pst. variicollis eggs was observed but the agent was not definitively confirmed. Results indicate Pst. variicollis will exhibit a wide host range in New Zealand but variability observed in the levels of defoliation between species may be linked to heritable traits that can be exploited through current breeding programmes.
\end{abstract}

Keywords Eucalyptus variegated beetle, EVB, incursion, Paropsis charybdis, Enoggera, Neopolycystus, NZDFI.

\section{INTRODUCTION}

In March 2016, the Australian chrysomelid Paropsisterna variicollis (Chapuis) (eucalyptus variegated beetle, EVB) was detected in New Zealand for the first time during routine Forest Biosecurity Surveillance at Te Pohue in Hawke's Bay, North Island (Rogan 2016). A biosecurity response was initiated by the Ministry for Primary Industries including delimitation and surveillance (Rogan 2016) while response options were assessed. The response was closed in autumn 2017 following confirmation that the beetle was widespread across parts of the Hawke's Bay. The pest potential of Pst. variicollis is not yet clear, but it is likely to affect a range of Eucalyptus species. Amongst these is a suite of drought- and frost-tolerant eucalypts being assessed by the New Zealand Dryland Forests Initiative (NZDFI) to develop a naturally ground-durable eucalypt timber resource in dryland regions of New Zealand (Apiolaza et al. 2011; Millen 2009), including the Hawke's Bay. Two other well-established Australian paropsines, Paropsis charybdis and Trachymela sloanei, already 
cause significant defoliation in some New Zealand eucalypt plantations (Walsh 1998; Murphy \& Kay 2000), and T. sloanei is a pest in California (Paine et al. 2000). Like these species, Pst. variicollis feeds exclusively on Eucalyptus leaves and young tender shoots. The four larval instars of Pst. variicollis feed gregariously, while solitary adults make notches on the leaf margins. In the Australian Capital Territory, Pst. variicollis has been noted as being common only after January, later in the season than the more serious pest Paropsis atomaria (Mo \& Farrow 1993). Several Paropsisterna spp. are known pests (Reid \& De Little 2013), including three species in Tasmania where they are endemic (Elek \& Patel 2016). The Tasmanian endemic Pst. selmani has caused significant defoliation of commercial E. nitens plantations in Tasmania since 1992 (Elek \& Patel 2016), and has more recently become an invasive pest in Ireland (Hogan 2011).

The current study aims to assess the initial incidence and defoliation caused by Pst. variicollis within durable eucalypt species trials already established close to the initial detection site. Controlled experiments could not be conducted as the beetle was, at the time, the focus of an open incursion response by the Ministry for Primary Industries, and as such no insect material could be handled or safely removed without compromising the response.

\section{MATERIALS AND METHODS}

Three durable Eucalyptus species trials in the Hawke's Bay region, (Alexander site 39 $37^{\prime}$ 36.876"S, $176^{\circ} 37^{\prime} 45.4434 " E$, Hawkes Bay Regional Council site (HBRC) 39० 14' 54.2862"S, $176^{\circ} 52^{\prime}$ 15.3798"E, and McNeill site $39^{\circ} 47^{\prime} 21.0372^{\prime \prime S}$, $\left.176^{\circ} 58^{\prime} 13.3926^{\prime \prime E}\right)$, were visited from 18 to 26 January 2017 to assess incidence of and defoliation by Pst. variicollis. Average annual rainfall for each site is 797, 1484 and $1061 \mathrm{~mm}$ respectively. Trees were planted in 2011,2013/14 and 2011/12 for the Alexander, HBRC and McNeill sites, respectively. Each trial consisted of multiples of single species plots of 49 trees at the Alexander and McNeill sites and 100 trees at the HBRC site, with plots of each species replicated and randomly arranged across each site. In total, 11 Eucalyptus species were assessed (Table 1). In each plot at the McNeill and Alexander sites, 30 inner trees (i.e. excluding perimeter trees) were assessed and 25 inner trees were assessed in the larger HBRC plots. Maximum tree top height was measured for all assessed trees using a 5-m E Reading staff (Accurate Instruments (NZ) LTD).

Table 1 Eucalyptus species, number of plots sampled, and the total number of trees assessed at each of three Hawke's Bay sites for paropsine defoliation and, in parentheses, for eggs, larvae and adults of Pst. variicollis and P. charybdis. Eucalyptus argophloia, E. eugenoides and E. notabilis were absent (A) from some sites.

\begin{tabular}{lccclll}
\hline \multirow{2}{*}{ Species } & \multicolumn{3}{c}{ No. plots assessed } & \multicolumn{3}{c}{ Total no. trees assessed } \\
\cline { 2 - 7 } & Alex. & HBRC & McNeill & Alex. & HBRC & McNeill \\
\hline E. argophloia & 2 & A & 2 & $38(20)$ & A & $37(26)$ \\
E. bosistoana & 4 & 2 & 2 & $92(43)$ & $50(30)$ & $46(29)$ \\
E. camaldulensis & 4 & 2 & 3 & $94(30)$ & $50(25)$ & $70(32)$ \\
E. cladocalyx & 2 & 2 & 2 & $35(12)$ & $50(31)$ & $46(27)$ \\
E. eugenoides & 3 & $\mathrm{~A}$ & 2 & $62(23)$ & $\mathrm{A}$ & $69(42)$ \\
E. globoidea & 3 & 2 & 2 & $61(27)$ & $50(27)$ & $46(35)$ \\
E. longifolia & 3 & 2 & 2 & $45(20)$ & $50(23)$ & $50(24)$ \\
E. macrorhyncha & 3 & 2 & 2 & $67(25)$ & $45(27)$ & $37(24)$ \\
E. notabilis & 2 & $\mathrm{~A}$ & $\mathrm{~A}$ & $42(20)$ & $\mathrm{A}$ & $\mathrm{A}$ \\
E. quadrangulata & 3 & 2 & 2 & $66(22)$ & $50(27)$ & $50(37)$ \\
E. tricarpa & 3 & 2 & 3 & $72(37)$ & $50(26)$ & $71(35)$ \\
\hline
\end{tabular}




\section{Defoliation assessment}

Levels of defoliation caused by chewing by paropsine beetles were visually assessed for each tree in the selected plots and assigned a damage score: $\mathrm{a}=$ no or little chewing $(<5 \%) ; \mathrm{b}=$ light chewing (5-25\% defoliation); $\mathrm{c}=$ moderate chewing (26$50 \%$ defoliation); $\mathrm{d}=$ moderately severe chewing (51-60\% defoliation). No damage greater than $60 \%$ defoliation was observed. Grades were based on the incidence (proportion of leaves of the whole crown being damaged) and severity (proportion of damage per leaf) of damage (adapted from the CDI Crown Damage Index method of Stone et al. 2003).

\section{Paropsine incidence}

Every second tree assessed for chewing damage was inspected closely for the presence of Pst. variicollis and $P$. charybdis. This resulted in the assessment of 46-102 trees per species, except E. notabilis ( $\mathrm{n}=20$ trees), which was present at only the Alexander site (Table 1). Three shoots that were reachable from the ground, and had similar amounts of foliage, were inspected per tree. Numbers of egg batches, larvae and adults of Pst. variicollis and $P$. charybdis were recorded. At the HBRC and $\mathrm{McNeill}$ sites, shoots were selected from different aspects and heights. However, at the Alexander site, trees were generally much taller, therefore shoots were selected from different aspects but only from the lower crown.

\section{Statistical analysis}

Defoliation data were analysed using the ordinal R package (Christensen 2015) in Rstudio (version 1.0.44). Cumulative link mixed models were built with function clmm to analyse the effect of species on insect damage. Function lme4 (Bates et al. 2015) was used to build generalised linear mixed-effects models (GLMM) using function glmer to assess the impact of tree species on adult insect abundance only, as egg and larvae counts were too low for statistical rigour. Each explanatory variable was dropped in turn and the optimal model was selected using the likelihood ratio statistic and AIC. The R function for model selection was anova in base $\mathrm{R}$.

\section{RESULTS AND DISCUSSION \\ Defoliation assessment}

Due to variable tree mortality (unrelated to this study) within plots at each site, the total number of trees available for assessment ranged from 135-219 per species, with the exception of E. notabilis $(\mathrm{n}=42)$ and E. argophloia $(\mathrm{n}=86)$, which were only present at one and two sties respectively. Most species at all three sites were assessed as suffering moderate to moderately severe paropsine chewing damage (Figure 1). Note that from a one-off visual assessment alone the causal agent (Pst. variicollis, P. charybdis or T. sloanei) of the leaf chewing could not be definitively known. Defoliation was highest at the McNeill site, with $26 \%$ and $71 \%$ of trees graded at damage levels c and $d$, respectively and no trees completely free of damage. The HBRC site, which was the wettest and had the youngest trees, also had the lowest damage levels (27\% at levels a and b). However, there was

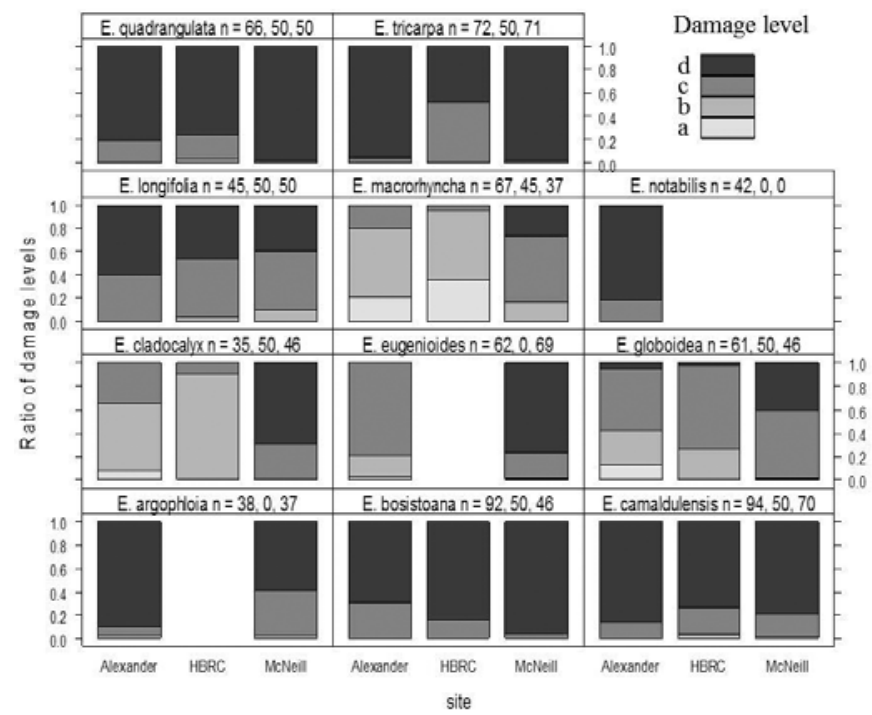

Figure 1 Proportion of inspected trees assigned to each level of chewing damage $(\mathrm{a}=$ no or little chewing $(<5 \%) ; \mathrm{b}=$ light chewing (5-25\% defoliation); $c=$ moderate chewing $(26-50 \%$ defoliation); $\mathrm{d}=$ moderately severe chewing (51-60\% defoliation) for each Eucalyptus species across three study sites. The number of trees assessed at each site is indicated by $n$ beside each species name respectively. 
no evidence that defoliation was correlated with average annual rainfall at a site.

Generally, E. macrorhyncha had the least chewing damage, followed by E. cladocalyx and then E. globoidea, the only monocalypt assessed. Eucalyptus macrorhyncha performed well at both the HBRC and Alexander sites, with $96 \%$ and $79 \%$ of trees respectively sustaining no or only light damage, but was more heavily defoliated at the McNeill site where $>50 \%$ of trees sustained moderate damage (Figure 1). Eucalyptus cladocalyx also suffered limited defoliation at both the HBRC and Alexander sites, (90\% and 57\% of trees showing only light damage), whereas all trees sustained moderate or moderately severe damage at the McNeill site. Performance of E. globoidea was more consistent, with mostly moderate damage at all sites (52\%, 72\% and 58\% for the Alexander, HBRC and McNeill sites respectively).

More than $60 \%$ of E. bosistoana, E. quadrangulata, E. camaldulensis, and E. argophloia sustained moderately severe damage in all sites, with E. bosistoana and E. quadrangulata being the most badly damaged. More than $95 \%$ of E. tricarpa also suffered moderately severe damage at the Alexander and McNeill sites, but less than half suffered the same at the HBRC site. Eucalyptus longifolia varied consistently between moderate and moderately severe damage, and E. notabilis was badly damaged but only present at one site.

A cumulative link mixed model (CLMM) was fitted to analyse whether or not tree species and tree height affected defoliation. Only trees for which height data was available were used in the analysis. Fixed effects for the model were tree species and tree height (with interaction), and random effects were plot nested within site. Centring of tree height was achieved by subtracting mean tree height from each tree height value. Each explanatory variable was dropped in turn and compared with the full model to select the optimal model. Models without species as a factor $(\mathrm{AIC}=1806.5)$, without tree height $(\mathrm{AIC}=1747.9)$, and without interaction of tree species and height $(\mathrm{AIC}=1744.2)$, respectively, were significantly different from the full model (AIC $=1721.7, a=0.001$ ). This result indicates that tree species and tree height significantly affected defoliation by paropsines. Predicted intercept estimates for each tree species at mean tree height $(5 \mathrm{~m})$ were produced for each damage level. Approximately $50 \%$ of E. macrorhyncha were predicted to incur no or light damage (Figure 2), but more than $80 \%$ of E. tricarpa, E. bosistoana, E. quadrangulata, E. camaldulensis and E. argophloia were predicted to incur moderately severe damage, implying these species are more preferred hosts of Pst. variicollis and/or P. charybdis.

\section{Paropsine incidence}

Paropsisterna variicollis, accounted for $73 \%$ of paropsine adults and nearly $100 \%$ of larvae and eggs, and was more abundant than $P$. charybdis at the Alexander and HBRC sites. Its abundance was similar to P. charybdis at the McNeill site. These results suggests that Pst. variicollis was the agent responsible for most of the chewing damage observed on average. The HBRC and McNeill

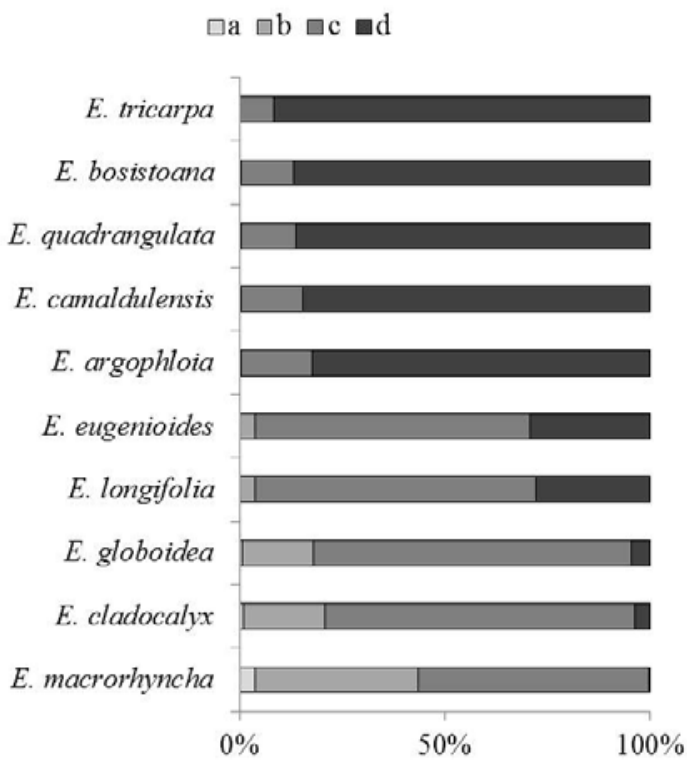

Figure 2 Proportion of trees of each species predicted to appear in each insect damage category (a, b, c or d) at the average tree height of $5 \mathrm{~m}$. Values were extracted from CLMM model. Eucalyptus notabilis was only present in one of the three sites and is excluded as insufficient data were available for inclusion in this analysis. 
sites had larger abundances of both species in all life stages than did the Alexander site. This may partly be due to the limitations of the sampling method which restricted sampling to shoots from the lower crown at the Alexander site, as the upper crowns were too high to reach.

The greatest abundance of Pst. variicollis adults were counted on E. bosistoana and E. tricarpa in all sites (Figure 3). In contrast, low counts were consistently found on E. globoidea, E. longifolia, and particularly E. macrorhyncha. Paropsisterna variicollis larvae counts were low on E. cladocalyx at both the Alexander and $\mathrm{McNeill}$ sites, but relatively high at the HBRC site (about 1.3 larvae per shoot), where mean counts were skewed because 40 early instar larvae were found on a single shoot.

Counts of Pst. variicollis and P. charybdis eggs and larvae were near zero on most shoots sampled (Figure 3). This indicates the sampling period of 18 to 26 January used here may not have been well timed to capture these important early developmental stages. Both Murphy and Kay (2000) and Jones \& Withers (2003) noted January as being between the first (spring) and second (summer) generations of $P$. charybdis and this may have also been the case for Pst. variicollis. As such, a generalised linear mixedeffect model was fitted only to the count data for adult Pst. variicollis. A full model was built with tree species and height as fixed effects, and tree nested within plot nested within site as random effects. Interaction between tree species and height could not be examined due to a lack of data. Nested models without tree species ( $\mathrm{AIC}=1888.453)$, tree height $(\mathrm{AIC}=1852.498)$ or both tree species and height $(\mathrm{AIC}=1890.222)$ respectively, were compared with the full model (AIC=1852.643) using the likelihood ratio statistic and AIC. The optimal model was that with only tree species as fixed effect, indicating tree species had a significant effect on Pst. variicollis adult abundance. Tukey-adjusted comparisons were used to compare post-hoc adult counts between each pair of tree species. Pst. variicollis adults were significantly more prevalent on E. bosistoana and E. tricarpa, followed by E. camaldulensis, and significantly less prevalent on E. macrorhyncha. Differences among all other species were not significant.

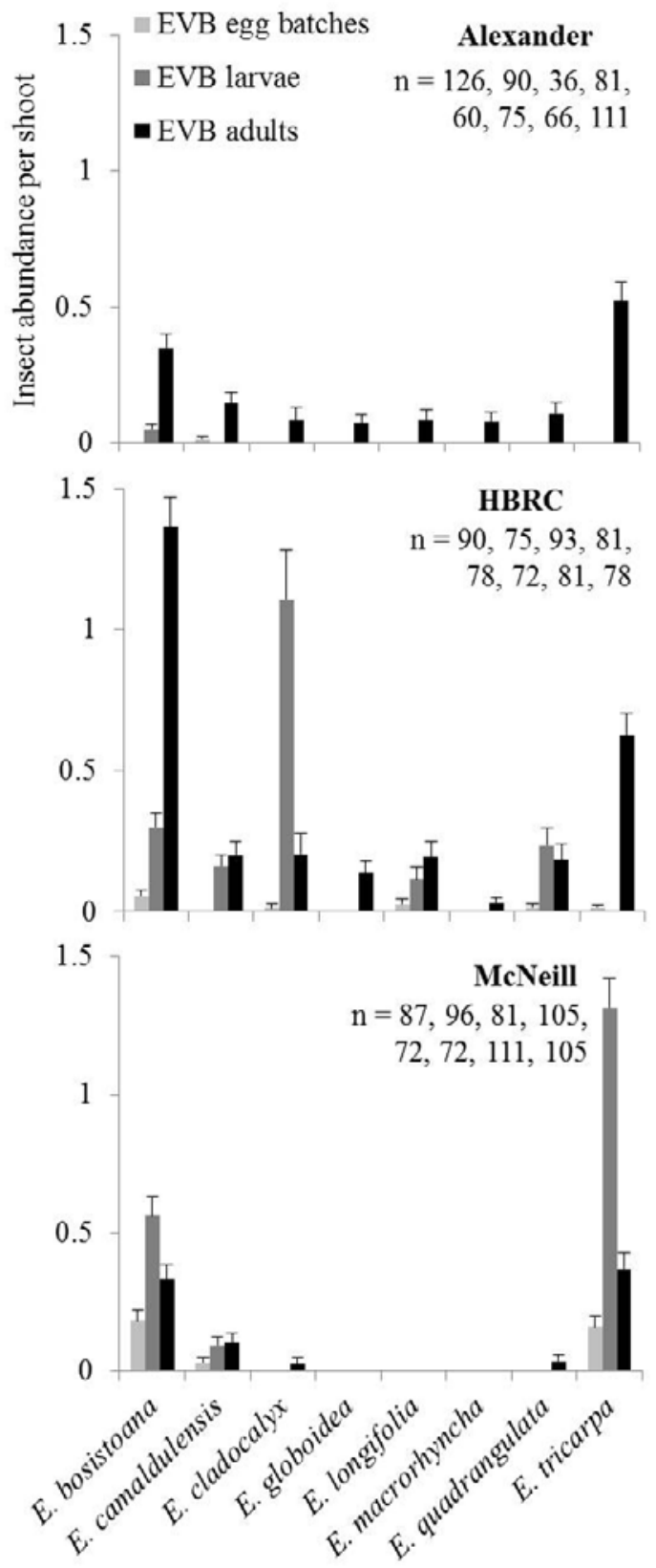

Figure 3 Average ( \pm SE) abundance of eggs, larvae and adult Pst. variicollis per shoot for the eight eucalypt species that were common to all three sites. The number of trees of each species inspected at each site is given as ' $n$ ' values representing each species in the order given on the $\mathrm{x}$ axis. 


\section{Egg parasitism}

Parasitism of Pst. variicollis eggs was detected on several occasions. As Pst. variicollis was still part of an active biosecurity response, no eggs could be collected to confirm parasitoid identity as either a new species, or as one of the three established species known to parasitise P. charybdis (Enoggera nassaui and Neopolycystus insectifurax, (Murray et al. 2008)) or the Acacia beetle Dicranosterna semipunctata (unidentified Neopolycystus sp., (Murray \& Withers 2010)). Late-stage parasitoid development was observed along with an adult parasitoid wasp assessing eggs, both of which were visually consistent with $N$. insectifurax. Egg batches exhibiting colour patterns more consistent with parasitism by En. nassaui were also seen. Both En. nassaui and N. insectifurax have been recorded from Pst. variicollis in the Australian Capital Territory (Mo \& Farrow 1993) and En. nassaui has been recorded as parasitising Pst. obovata, which is thought to be part of a species complex with Pst. variicollis (T. Withers pers. comm.), in Tasmania (Murphy 2006). As such, parasitism of Pst. variicollis by En. nassaui and N. insectifurax would be expected in New Zealand.

\section{CONCLUSION}

Informal observations and formal delimitation surveys to date indicate Pst. variicollis is present and feeding voraciously on numerous eucalypt species within the Hawke's Bay region. This study attempted to quantify some of these observations in order to better understand the risk posed to a select group of eleven eucalypt species that were already established near the incursion point as part of an important new breeding programme for naturally durable timber. Shortly after the detection of Pst. variicollis, Rogan (2016) observed that, unlike the other established pest paropsines ( $P$. charybdis and T. sloanei), larvae were still active in late April 2016. This raised concern within the wider eucalypt forestry industry that Pst. variicollis could become an even more damaging pest than these other species. Given previous experiences with $P$. charybdis and more recently the eradication attempt against Paropsisterna beata (Newman) (Yamoah etal.2016), thereislittle reason to expect Pst. variicollis could not eventually spread throughout New Zealand wherever suitable host species are present if quick action is not taken to contain it. Exactly which eucalypt species will be suitable hosts, and the degree of impact that preferred species will sustain, is of intense interest as groups including the NZDFI are trying to expand the eucalypt industry tries and gain grower confidence. Results from two assessment methods used here indicate that, of the species assessed, E. macrorhyncha and E. cladocalyx are the least susceptible to Pst. variicollis, while E. bosistoana, E. tricarpa, E. camaldulensis and E. quadrangulata are the most.

The lack of Pst. variicollis eggs and larvae observed on most hosts, and the variability in damage levels sustained by each species between sites, may reflect the timing of the study, which possibly occurred between generations. A more reliable estimate of host preferences will result from future studies that optimise sampling to detect oviposition and larval feeding. Variability in damage may also relate to the fact that defoliation could have been caused by a combination of Pst. variicollis, $P$. charybdis and T. sloanei. Although Pst. variicollis was detected with significantly higher abundance during this study, the other beetles, each of which may exhibit different species preferences, could have contributed to defoliation in the weeks prior to the assessment. The variability in defoliation is, however, also considered somewhat promising with regard to the NZDFI breeding programme. As numerous genetically distinct families are present in the trials (Apiolaza et al. 2011), some of the variation in damage sustained could be linked to genetically heritable tolerance to defoliation and lower palatability, and this will be the focus of future assessments. Also encouraging was the observation that at least one species of parasitoid is successfully attacking Pst. variicollis eggs in the field which has potential to reduce population growth of the new pest beetle.

\section{ACKNOWLEDGEMENTS}

This research was funded by the New Zealand Forest Owners Association and the Partnership for Speciality Wood Products Contract ID: 
FFRX1501. We thank Ben McNeill, Rick Alexander and the Hawke's Bay Regional Council for access to their properties; Kevin Thomsen for transportation; Jack Burgess and Satoru Kuwabara for field work support and tree height data; and Dr Daniel Gerhard, Dr Elena Moltchanova and Dr Luis Apiolaza for statistical advice. We also thank Toni Withers (Scion) for her helpful comments on an earlier version of this manuscript.

\section{REFERENCES}

Apiolaza LA, McConnochie R, Millen P, Van Ballekom S, Walker JCF 2011. Introducing durable species to New Zealand drylands: genetics of early adaptation of Eucalyptus bosistoana. In: Walker J ed. Developing a Encalypt Resource: Learning from Australia and elsewhere. New Zealand Dryland Forests Initiative Workshop. Pp. 137-145.

Bates D, Maechler M, Bolker B, Walker S 2015. Fitting linear mixed-effects models using lme4. Journal of Statistical Software 67(1): $1-48$.

Christensen RHB 2015. ordinal - Regression models for ordinal data. $\mathrm{R}$ package version 2015.6-28. http://www.cran.r-project.org package $=$ ordinal $/$.

Elek JE, Patel V 2016. The threat to Eucalyptus plantations from an emerging Tasmanian leaf beetle pest: Paropsisterna selmani (Coleoptera: Chrysomelidae). Australian Forestry 79(4): 256-260.

Hogan FG 2011. Outbreak of an invasive paropsine beetle in south-west Ireland: preference, performance and damage to Eucalyptus. Journal of applied entomology 135: 621-633.

Jones DC, Withers TM 2003. The seasonal abundance of the newly established parasitoid complex of the Eucalyptus tortoise beetle (Paropsis charybdis). New Zealand Plant Protection 56: 51-55.

Millen P 2009. NZ dryland forests initiative: a market focused durable eucalypt R\&D project. In: Apiolaza L, Chauhan SVS, Walker JCF eds. Revisiting Eucalypts. Wood Technology Research Centre, University of Canterbury, Christchurch, New Zealand Pp. 57-74.
Mo JH, Farrow RA 1993. Estimation and correction of egg mortality rates from sample data of two coexisting leaf beetles (Coleoptera: Chrysomelidae: Paropsini). Journal of the Australian Entomological Society 32: 85-92.

Murray TJ, Withers TM 2010. Detection and identification of a self-introduced parasitoid of the Acacia tortoise beetle. New Zealand Plant Protection 63: 282.

Murray TJ, Withers TM, Mansfield S, Bain J 2008. Distribution and current status of natural enemies of Paropsis charybdis in New Zealand. New Zealand Plant Protection 61: 185-190.

Murphy B 2006. Biological control of Paropsis charybdis Stål (Coleoptera: Chrysomelidae) and the paropsine threat to Eucalyptus in New Zealand. Unpublished PhD thesis, University of Canterbury, Christchurch. 98 p.

Murphy B, Kay M 2000. Paropsis charybdis defoliation of Eucalyptus stands in New Zealand's central North Island. New Zealand Plant Protection Society 53: 334-338.

Paine TD, Dahlsten DL, Millar JG, Hoddle MS, Hanks LM 2000. UC scientists apply IPM techniques to new Eucalyptus pest. California Agriculture Magazine 54(6): 8-13.

Reid CAM, De Little DW 2013. A new species of Paropsisterna Motschulsky, 1860, a significant pest of plantation eucalypts in Tasmania and Ireland (Coleoptera: Chrysomelidae: Chrysomelinae). Zootaxa 3681(4): 395-404.

Rogan, BJ 2016. Biosecurity inspector reports Paropsisterna variicollis in Hawke's Bay. Forest Health News 269. Scion, Rotorua, New Zealand. Stone C, Parsons M, Matsuki M, Carnegie AJ 2003. Pest and disease assessment in young eucalypt plantations: field manual for using the Crown Damage Index, Bureau of Rural Sciences.

Walsh PJ 1998. Report to the New Zealand Farm Forestry Association on a survey of insect pests and their known distributions as at 23 March 1998. Tree Grower 19(2): 36-39.

Yamoah E, Voice D, Gunawardana D, Chandler B, Hammond D 2016. Eradication of Paropsisterna beata (Newman) (Coleoptera: Chrysomelidae) in a semi-rural suburb in New Zealand. New Zealand Journal of Forestry Science 46:5 